\title{
Von Mund zu Mund
}

\section{Bernhard Gurtner}

Dr. med., ehemaliger med. Chefarzt Spital Wetzikon, SGAIM-Mitglied

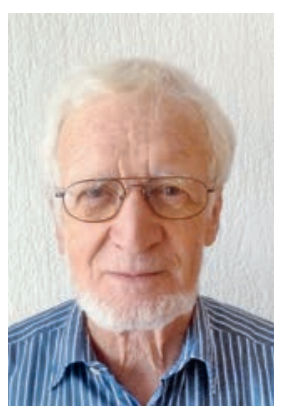

Ein Medizinstudent spazierte in Mexiko-City mit seinem Hund, der neugierig alles beschnüffelte, was auf dem Weg lag. Plötzlich stürzte das Tier röchelnd zu Boden. Der in erster Hilfe ausgebildete Student begann sofort eine Mund-zu-Schnauze-Beatmung, wurde aber selbst vergiftet, erbrach und verlor das Bewusstsein. Der Hund starb, der Student konnte im nächsten Spital gerettet werden, weil der Notfallarzt einen für Blausäure typischen Bittermandelgeruch bemerkte und sofort eine wirksame Behandlung einleitete.

Erfolgreicher für das Tier war eine Mund-zu-RüsselBeatmung im Zoo Hannover, wo ein Tierpfleger einem Tapir-Baby das Leben retten konnte. Viehzüchter und Tierärzte unterstützen seit jeher asphyktische Neugeborene mit Atemspende. Heute bewahren sie Ambubeutel davor, die kleinen Kälber oder Säuli eigenmundig aufblasen zu müssen.

Der in erster Hilfe ausgebildete Student begann sofort eine Mund-zu-Schnauze-Beatmung, wurde aber selbst vergiftet.

In Badeanstalten gab es einst Instruktionstafeln, die zeigten, wie man Ertrunkene mit Wiederbelebungsgymnastik nach Holger-Nielsen reanimieren könne. Die Methode war nur selten erfolgreich und wurde $a b$ 1960 durch die dem innigen Küssen verwandte Mundzu-Mund-Beatmung abgelöst, kurz darauf durch eine Mund-zu-Nase-Technik. Sie erregt weniger Ekel und hygienische Bedenken. Hervorragende Nasen bieten den Souffleuren auch einen besseren Ansatzpunkt als schmale Lippen.

Mund-zu-Mund-Kontakte sind nicht nur ein Lieblingsthema heisser Filme und Romane, sondern eine gesundheitliche Gefahr, vor der die Verliebten üblicherweise beide Augen schliessen. Die Menschheit hat trotzdem oder gerade deshalb glücklich überlebt. Das bei Jugendlichen verbreitete Pfeiffer'sche Drüsenfieber nennt man «kissing disease», weil es durch Küssen übertragen werden kann. Es bringt Assistenzärzte in Verlegenheit, wenn sie gleichzeitig mit zwei Spitallaborantinnen daran erkranken.
Nicht nur infektiöse Erreger können durch ein «Müntschi» übertragen werden. Eine junge Frau erlitt einen schweren allergischen Schock, nachdem sie von ihrem Freund geküsst worden war, der kurz zuvor eine Garnele genossen hatte. Die Patientin hatte schon

In Pflegeheimen wurden gelegentlich künstliche Gebisse bei der Reinigung verwechselt.

früher mit heftigem Nesselfieber auf Hummer oder Krevetten reagiert, aber nicht gewusst, dass ein Gutenachtkuss so umwerfende Folgen haben kann. Auch Patienten mit Allergie auf Erdnüsse sind empfindlich auf kleinste Spuren und müssen schmusefreudige Partner bitten, nach Nussgenuss den Mund gut zu spülen, was nicht immer genügt, so dass sich die Liebenden für Küsschen oder Nüsschen entscheiden müssen.

In Pflegeheimen wurden gelegentlich künstliche Gebisse bei der Reinigung verwechselt, was zu zähnefletschenden Auseinandersetzungen führte. Einer Pflegeschülerin bereitete es die allergrösste Mühe, die rechtmässigen Besitzerinnen wieder ausfindig zu machen, deren Zahnprothesen sie gemeinsam im selben Waschbecken vorgespült hatte. Man kann Rationalisierung im Gesundheitswesen auch einmal übertreiben.

Zur Rationierung gezwungen war ein verarmtes Ehepaar, das sich nur eine gemeinsame Prothese leisten konnte und deshalb gestaffelt essen musste. Diese unappetitliche Kalendergeschichte erzählten unsere künstlich bezahnten Grosseltern. Noch selbst erlebt habe ich, dass sich Hinterbliebene im Spital um eine neue Zahnprothese stritten, die eine friedlich verstorbene Angehörige hinterlassen hatte. So sparsam war man hierzulande, als kariöse Jünglinge die dritten Zähne bereits zur Konfirmation geschenkt erhielten. Aber das war vielleicht nur ein Gerücht, das ungeprüft von Mund zu Mund weitergereicht wurde, bis uns die Dentalhygienikerinnen eine neue Generation mit blendend weissen Zähnen geschenkt haben, die sich täglich mit Selfies in den sozialen Medien lächelnd vernetzt. 